\title{
DISCENTES NA DOCÊNCIA - EXPERIÊNCIAS DIALÓGICAS
}

Liliane Ferreira Mundim ${ }^{1}$

\section{Resumo}

Este artigo discute a prática docente de discentes em formação. Tendo como foco uma ação desenvolvida através de um projeto de pesquisa institucional, discutirei alguns procedimentos metodológicos, construídos pelos discentes para suas próprias experiências pedagógicas. Discutirei também alguns caminhos que possibilitem a potencialização da autonomia didática, o exercício da investigação e da reflexão sobre e na ação pedagógica e a responsabilidade de se pensar, planejar, experimentar e avaliar criticamente tais ações. Apontarei também como proposta de trabalho a abordagem do processo colaborativo como metodologia capaz de promover essa capacidade de autonomia e de criação.

Palavras-chave: formação do professor, experiência pedagógica, processo colaborativo.

Abstract

This article discusses the practice of teacher students in training. Focusing on a program developed by an institutional research project, discusses some methodological procedures built by students for their own learning experiences. I will also discuss some ways that enable the enhancement of teaching autonomy, the exercise of research and reflection on teaching and action, and responsibility to think, plan, experiment and critically evaluate these actions. It also points to the approach of the collaborative process as a methodology capable of promoting the autonomy and capacity building.

Keywords: teachers' training, pedagogical experience, collaborative process. 
N

campo Pedagogia do um dos fatores problematizantes que mais afetam a prática docente gira em torno da elaboração de planejamentos específicos, voltados para os diferentes contextos sócio-culturais

No cotidiano de sala de aula, lidando com estudantes licenciandos, venho observando que muitos já estão inseridos no mercado de trabalho, desenvolvendo projetos em espaços diversificados, construindo seus próprios planejamentos a partir de escolhas e recortes pessoais, baseados nas experiências adquiridas durante o processo do curso de graduação. Esses agenciamentos são interrelacionados a diferentes concepções, tanto artísticas, como pedagógicas.

Ministrando as disciplinas Metodologia do Ensino do Teatro e Estágio Supervisionado, no Curso de Teatro, Modalidade Licenciatura, oferecido pela UNIRIO, percebo nos discursos da maioria dos alunos, as dificuldades que se revelam, principalmente quando se deparam diante de grupos diversos, para os quais necessitam elaborar um planejamento de trabalho.

Mediante essas questões, iniciei um projeto de pesquisa com o objetivo de dialogar com essas demandas. Denominado Diferentes Olhares sobre as práticas pedagógicas tem como ideia central instigar a reflexão sobre essas experiências, dentre elas: a análise diagnóstica do grupo para o qual se vai planejar e sua contextualização.

Fundamentado em uma perspectiva dialógica, os encontros visam a potencialização da autonomia didática desses futuros docentes, incentivando o exercício da investigação, da reflexão sobre e na ação, incentivando também a prática da escrita e do registro das ações

1 Professora efetiva da Universidade Federal do Estado do Rio de Janeiro - UNIRIO - Centro de Letras e Artes Departamento de Ensino de Teatro,. Também é coordenadora do Núcleo de Ensino de Teatro - UNIRIO. desenvolvidas. $\mathrm{O}$ processo cria essa dinâmica de pensar, planejar, experimentar e avaliar criticamente as ações.

Nessa trajetória observo que os licenciandos se baseiam tanto nos pensadores referenciais da área da Pedagogia do Teatro, como também dialogam com pensadores das diferentes áreas do conhecimento ligados aos teóricos da Educação, da Psicologia, Filosofa, Sociologia, Antropologia, dentre outros, que atravessam suas discussões e reflexões. Tais conexões acabam por influenciar e modificar suas práticas. Embora ainda incipientes tais correlações parecem instigá-los a desdobramentos de pesquisa e articulações com outras áreas de conhecimento.

Tracei então, como proposta de ação metodológica três eixos temáticos, que abrangem: análise crítico-reflexiva, através do levantamento do repertório de jogos já conhecidos como referências do trabalho de Pedagogia do Teatro, dentre outras metodologias que subsidiam as práticas teatrais; produção e sistematização, através do registro e sistematização das atividades realizadas: fichas de acompanhamento, fotos, filmes, pranchas e textos diversos; análise das fontes através de pesquisa investigativa sobre as fontes utilizadas pelos alunos-pesquisadores.

Comoembasamentoe princípiofilosófico, me inspiram as concepções do processo colaborativo. Tal conceito, proposto e experimentado por Antonio Araujo e é conhecido como "uma metodologia de criação em que todos os integrantes, a partir de suas funções artísticas específicas têm igual espaço propositivo, trabalhando em hierarquias - ou com hierarquias móveis, a depender do momento de processo - e produzindo uma obra cuja autoria é compartilhada por todos (ARAUJO,2002).

Esses procedimentos têm sido parte integrante de meu processo de trabalho, trilhado de forma dialógica, que prioriza a autonomia, a divisão de tarefas, a iniciativa própria, a horizontalidade, a polifonia de vozes, a troca permanente e a formação contínua.

Estão inscritos atualmente no projeto, seis alunos em diferentes períodos do curso. Como 
critério obrigatório, o aluno precisa ter cursado a disciplina ${ }^{2}$ - Diretor do Teatro da Vertigem e professor do Departamento de Artes Cênicas da ECA-USP

Percebo através desse cotidiano um amplo panorama de abordagens pedagógicas que suscitam reflexões que acabam por contaminar todo o grupo, que vêm tornando o trabalho bem interessante. Alguns recortes construídos a partir dessas discussões demonstram que esses experimentos refletem possivelmente, a maneira pela qual esses estudantes absorvem o conhecimento adquirido no lócus universitário.

Como alguns exemplos de recortes, cito algumas das falas dos próprios alunos-pesquisadores.

Juliana Ibraim tem como objeto de reflexão e prática, o drama como método de ensino, baseado nas abordagens da professora Beatriz Cabral e, nesse momento se debruça sobre a leitura de textos relacionados às pesquisas da autora (alguns deles citados na bibliografia geral). Porém, mesmo lendo os textos e articulando um planejamento para o grupo que vem ministrando aulas em São Gonçalo, com o qual vem trabalhando, percebeu a necessidade da testagem, junto ao grupo de pesquisa, do experimento planejado.

Suas reflexões apresentam aspectos importantes onde cita

o lugar do professor-personagem e sua importância no jogo; a veracidade que este deve apresentar para se tornar mais instigante a experiência; a relevância que os objetos inseridos no jogo devem ter; a importância da participação integral do todo o grupo, nas etapas do processo, e como isso é rico para a associação das informações e relações levantadas por cada integrante (MUNDIM, 2010/2011).

2 Metodologia do Ensino de Teatro. Com encontros semanais de três horas de duração o planejamento é realizado no coletivo, observand o o fluxo e a necessidade de cada momento. Praticamente todos desenvolvem ou já desenvolveram projetos pessoais em diversos contextos e esses diferentes universos revelados para o grupo são compartilhados, experimentados e discutidos, fazendo do encontro uma fonte de pesquisa, troca e avaliação permanente dos processos.
Sendo assim, ao experimentar com um grupo de alunos em outro espaço extra-universidade vem levantando vários questionamentos que pretende dar continuidade em sua pesquisa; dentre eles:

a interação professor aluno que se dá cenicamente é uma troca de experiências, pois o professor assume um personagem no processo e os alunos devem embarcar nessa experiência também, assumindo personagens distintos, criando cenas e improvisando ao decorrer da experiência; a criação coletiva que é gerada independente do pré-texto que o professor sugira; como uma criação coletiva, pois se abrem portas para que os participantes criem; os diferentes modos de abordar o teatro como uma forma de trabalhar a dramaturgia, criação de pequenas cenas que vão se desenvolvendo até chegar a um resultado final; o incentivo da escrita e da criação voltadas para crianças e jovens; a autonomia e a liberdade de criação que promove nos jovens, cujos hábitos, na atualidade estão envolvidos pelo vídeo game (MUNDIM, 2010/2011).

\section{Juliana ressalta também que}

a abordagem do drama, do texto como pré-texto e da criação não têm como objetivos, substituir os jogos eletrônicos nem desconsiderar o conhecimento adquiridos pelos mesmos, mas sim, proporcionar outras condições de criação, autonomia e envolvimento. E que possam, através da linguagem teatral, vivenciar experiências e práticas através do próprio corpo, promovendo assim abertura e potencialização de diferentes percepções (MUNDIM, 2010/2011).

Lucas Nascimento se baseia em investigações em torno do espaço (mais especificamente o espaço público) e como elemento fundador do jogo teatral. Suas experiências já estão inseridas na perspectiva da docência e são articuladas às metodologias de pedagogos e encenadores que exploram a cidade, dialogando com o pensamento de Michel de Certeau, em $A$ invenção do cotidiano (CERTEAU, 2008). 
Referendado em um dos encontros do projeto, que teve como local uma praça de alimentação de um shopping no bairro de Botafogo, tece reflexões sem abrir mão de uma poesis própria:

(...) nos debruçamos, por algum tempo, sobre uma relação íntima (quase secreta) do aluno/ator com os espaços onde trabalhamos. Mais deixamos que os espaços nos trouxessem imagens do que propusemos para possíveis espectadores. Entregamo-nos ao apagamento, tentando gerar o mínimo de estranheza, enquanto relacionávamos textos a espaços e percursos, criando imagens poéticas para si próprios: o esforço maior era o de nos inserir na paisagem e no fluxo.(...) Além de um exercício de percepção, de escuta, era o estopim para uma criação dramatúrgica (MUNDIM, 2010/2011).

Articula o processo vivenciado ao pensamento de Michel de Certeau:

\begin{abstract}
(...) Se, por um lado, aquele espaço definia comportamentos (considerando-o à distância, sincronicamente as pessoas o ocupavam, comiam e iam embora), por outro, está sujeito tanto a um tempo "externo", o tempo da cidade (...) quanto às pequenas ações das pessoas, que anonimamente, cotidianamente, fazem escolhas: ocupam mais determinadas áreas e estabelecimentos, falam alto aqui, silenciam ali, criam o espaço com passos, ritmos, sons; eles podem modificar os espaços, os transformando em lugares de passagem ou de convivência (MUNDIM, 2010/2011).
\end{abstract}

Interessante ressaltar que suas observações acabam por ampliar seu olhar para a abordagem do espaço como indutor, enquadramento cênico ou área de jogo.

Ele nos fala que "enquanto explorávamos na praça de alimentação, minimamente transformávamos a praça de alimentação em praça de estudo, de observação, de criação dramatúrgica..." (MUNDIM, 2010/2011).

Comparando as caminhadas dos pedestres ao ato de falar, Certeau afirma que caminhar está para o sistema urbano como a enunciação (o speach act) está para a língua"(...) "é um como um processo de apropriação do sistema tomográfico pelo pedestre (...) como uma realização espacial do lugar (...) como uma enunciação, o caminhante faz com que a ordem espacial, suas proibições e possibilidades apareçam, assim como "as desloca e inventa outras, pois as idas e vindas, as variações ou as improvisações da caminhada privilegiam, mudam ou deixam de lado elementos espaciais (CERTEAU, 2009, p. 164-165).

Jaqueline Vasconcelos atua como bolsista no Projeto de Extensão - Teatro na Prisão (UNIRIO), que se desenvolve na penitenciária masculina de segurança máxima Lemos de Brito/Bangu 6 (RJ). A aluna também tem como reflexão a espacialidade e sua relação com o teatro, articuladas às abordagens de Jean Pierre Ryngaert. No entanto, amplia a investigação desses conceitos relacionados à Pedagogia do Teatro e reflete as questões desse espaço prisional sob o ponto de vista histórico de Michel Foucault em "Vigiar e Punir", propondo também um contraponto pelo viés da fenomenologia do espaço, a partir dos conceitos pressupostos pelo filósofo Maurice Merleau-Ponty.

A aluna considera que esses agenciamentos contribuem para se pensar o espaço aprisionador do ambiente da cadeia, não somente como lócus repleto de prédeterminações. Tais referências, segundo suasreflexõesagem como" atravessamentos que dilatam as abordagens e os conceitos que venho investigando, permitindo outros olhares para questões como: - a percepção da espacialidade; - o espaço como indutor do jogo teatral e da cena;- a elaboração de novos olhares para o mesmo lugar expressivo" (MUNDIM, 2010/2011).

Admite que o grupo de pesquisa colabore com outros olhares sobre seu fazer pedagógico, pois, em sua fala apontaos como “(...) trocas teóricas que, mesmo não dialogando profundamente com meu objeto investigativo, terminam porinterferir significativamente nas reflexões que venho elaborando" (MUNDIM, 2010/2011). 
No entanto, nem todos se envolvem de imediato com a ação da pesquisa investigativa, mostrando-se algumas vezes temerosos e inseguros diante da possibilidade de refletir teoricamente sobre o que estão desenvolvendo. A velha dicotomia teoria $\mathrm{X}$ prática ainda permanece.

Porém, tento desconstruir esse olhar, no sentido de instigar o pensamento reflexivo e crítico dos alunos, fazendo-os ver seus fazeres como algo dotado de pensamento teórico ainda embrionário, porém latente.

Joaquim Vicente inicialmente demonstrou algumas dúvidas quanto à relevância de participar de um grupo de pesquisa, posto que ainda não houvesse recortado seu objeto de investigação. Porém, seu estágio de docência na escola de aplicação - CAP's da UFRJ foi fundamental para detonar insights teóricos em seus fazer pedagógico. Articulou seu interesse em experimentar outras possibilidades metodológicas a partir de suas vivências nas oficinas: "Mundo Partido I e II", dentro do projeto Puentes, sobre dramaturgia contemporânea. Tais encontros trabalharam no viés na dramaturgia atoral e foram percebidos por Joaquim como um rico material de repertório vasto para que elaborasse propostas pedagógicas. As oficinas oferecidas pelo ator/autor e premiado dramaturgo espanhol José Sanchis Sinisterra ${ }^{3}$ em 2007 e 2008 no Teatro Poeira (RJ), das quais o aluno participou ativamente, foram reinventadas e adaptadas para os alunos do estágio.

A partir dessa experiência docente, teceu reflexões que vêm acrescidas de criação e elaboração de desdobramentos metodológicos. Sua fala denota essa assimilação da experiência como algo fértil e capaz de instigar e promover ações pedagógicas:

\footnotetext{
3 José Sanchis Sinisterra (Valencia, 1940) é um dramaturgo e diretor teatral espanhol, um dos autores mais premiados e representados do teatro espanhol contemporâneo e um grande renovador da cena espanhola. Ele também é conhecido por seu trabalho de docente e pedagogo no campo teatral. Sua relação com o Brasil é intensa e seu último texto encenado aqui “Máquina de Abraçar" (direção de Malu Galli) foi muito elogiado.
}

\begin{abstract}
Ciente de que o jogo é bom quando as regras são claras, considerei também que, pela faixa etária, meu material didático precisava de um apelo visual. Elaborei materiais que suscitassem essas motivações. (...) A aplicação foi muito interessante. A cada turma eu aprimorava o método de aplicação. O jogo obteve uma ótima resposta. (...) posso afirmar que não devemos subestimar a capacidade dos alunos. (...) nos encontros do Projeto de Pesquisa, estou descobrindo aos poucos, muitos pontos em comum com as inquietações que brotam nesse coletivo do grupo (MUNDIM, 2010/2011).
\end{abstract}

Observo também que as singularidades se revelam nas reflexões. A aluna-pesquisadora Taianã Mello, já inicia sua fala de forma abrangente, tentando conciliar o "ser aluno, criador, performer". Está no início de suas investigações sobre o teatro e suas possíveis contribuições para a autonomia criativa.

(...)a tentativa de desenvolver uma metodologia para o ensino da Performance num contexto escolar nasce do desejo de um eu-atriz em compreender melhor os processos criativos da performance arte e de construir dentro e a partir deles. Desejo que cresce e encontra consistência na investigação de um eu-aluna, e se firma no desejo provocativo de um eu-licencianda (MUNDIM, 2010/2011).

Indiquei, portanto algumas leituras referentes à Performance, especificamente os artigos e textos diversos, organizados pelo Prof ${ }^{\circ}$ Zeca Ligiéro, coordenador do Núcleo de Estudos da Performance AfroAmeríndia (NEPAA) e professor na mesma instituição para que pudesse ampliar seu repertório de investigação o que, relata a aluna foi de suma importância para a articulação com suas reflexões teóricas.

Ressalta Taianã que "nesse caminho de encontros, de modo particular com o texto de Schechner, bem como junto ao coletivo de colegas que conosco compartilham encontros periódicos de reflexão e discussão, que todos aqueles desejos, que de fato somam um, encontraram eco e se corporificaram em questões" (MUNDIM, 2010/2011). 
Desde então a aluna passou a articular outros conceitos que abrangem, não somente os experimentos do Viewpoints, abordagem anteriormente investigada pela aluna, como também, os da Performance, o que fez com que levantasse outras questões: "Porque, para que, para quem e como a performance é uma possibilidade de pesquisa e experiência? A performance é uma possibilidade de pesquisa e experiência dentro do ambiente escolar?" (MUNDIM, 2010/2011).

E elabora projetos próprios que possam, além de se desdobrarem em perspectivas pedagógicas, também travar, segundo a aluna um "diálogo entre as dimensões teóricas e práticas - não somente no desenvolvimento de seu registro escrito, mas também dentro da sala de aula (...) através de jogos de improvisação contemporâneos, como os View Points, o Rasa Box, dentre outros, pretendo investigar uma proposta metodológica capaz de desmistificar e, ou mesmo apenas, aproximar a linguagem da performance arte do cotidiano da sala de aula" (MUNDIM, 2010/2011). Como um espaço possível para que se discuta o cotidiano dos alunos, desde relações familiares até inquietações de ordem social e política, estimulando sempre a utilização do discurso estético como via de expressão prioritária.

Considera também a validade desses encontros dizendo que "a oportunidade de compartilhar ideias, que por vezes nos parecem ainda soltas, também tem sido um espaço onde nos expomos, (...) as trajetórias de nosso pensamento nos revelam até mais do que as conclusões as quais chegamos através delas" (MUNDIM, 2010/2011).

Outro foco interessante levantado como discussão, extrapola as fronteiras escolares e investiga a formação de espectadores jovens. A aluna Alessandra Biá, em momento de defesa de Trabalho de Conclusão de Curso (TCC) levanta questões sobre apreciação, acesso e conhecimento dos códigos teatrais nesse nicho da sociedade. Ressalta suas inquietações colocando em jogo: teatro de guerra $X$ teatro de resistência. Em sua fala essa curiosidade se revela que "já me questionava sobre a figura do jovem e sua relação com o teatro. Sabíamos muito sobre o teatro infantil, muito sobre o adulto... mas, quem pensava no público jovem? Eu estava pensando" (MUNDIM, 2010/2011).

E cita Desgranges quando esse nos fala que "o dito teatro de arte não é mais um movimento de guerra e, sim, de resistência, tal a indiferença a que foi relegado" (2002, p. 23).

Alessandra, vivendo esse rito de passagem rito de passagem da discência para adocênciainstitucionalizadaconsidera os encontros de nosso projeto de pesquisa como algo relevante nesse momento crucial de sua vida acadêmica onde, segundo a aluna "cada pequena ideia se desmembra e se transforma, se consolida e se clarifica a cada reunião. $\mathrm{O}$ compartilhamento de vivências me aponta possibilidades" (MUNDIM, 2010/2011).

Percebo então que outros olhares sobre as experiências vão se configurando e proponho que possamos rever nossas ações pedagógicas pautadas na relação com a produção de nossos estudantes, de forma a considerar tais produções, parte integrante da construção de conhecimento acadêmico, dando-lhes o devido valor e potência. Essas enunciações são como micro partículas que dão consistência e embasamento ao macro espaço acadêmico, que ainda se pauta muitas vezes, em paradigmas que contrapõem a figura docente a do discente.

$\mathrm{Na}$ medida em que vivemos uma contemporaneidade cujo acesso irrestrito às diversas tecnologias, abre janelas para inúmeras áreas de conhecimento, múltiplas redes sociais e formas interativas, que se interligam e promovem permanentes discussões e debates; cuja velocidade de informação amplia as possibilidades de interação e interferências nos processos de criação que se tornam cada vez mais intensos; 
urge que possamos, no lócus acadêmico aproveitar as oportunidades para criarmos e construirmos outras formas de atuação e condições para diferentes e criativas dinâmicas de aprendizagem.

Essas experiências, inseridas na discussão de um projeto institucional, me instigam a, cada vez mais pensar o projeto pedagógico da universidade atravessado por esses agenciamentos múltiplos e polifônicos. Percebo também a importância de dar continuidade a esse processo, através de uma política focada na Formação Continuada desses discentes, futuros docentes. Além dessas questões, aponto como fator problematizante que tal processo investigativo do projeto em questão, possa traçar um levantamento analítico e critico que contribua provavelmente, para subsidiar o processo avaliativo do Projeto Político Pedagógico da Universidade, referente ao Curso de Teatro - Modalidade Licenciatura.

Possivelmente muitos de nossos discentes licenciandos não exercem a docência somente para subsistência, mas também como forma de se colocarem presentes e atuantes no mundo do trabalho. Portanto, considerar esses e outros tantos fatores é afirmar o papel da universidade como importante lócus transformador da sociedade.

A Universidade mais do que nunca deve estar atenta aos avanços que provavelmente vão ditar diretrizes, que possam mudar o curso de muitas histórias de exclusão, abismos sociais e econômicos que vêm afastando do mundo acadêmico os ventos das mudanças significativas. Romper as fronteiras da produção deconhecimento, construindo seus aportes de forma colaborativa e dialógica pode colocar lado a lado docentes e discentes, trilhando caminhos, menos solitários e mais solidários. O que se revela através do processo coletivo e cooperativo, nos alimenta e nos fortalece; impulsionandonos para outros devires mais ousados.

\section{Referências bibliográficas}

CABRAL, Beatriz. Drama como método de ensino. São Paulo: Hucitec, 2006.

O professor-artista: perspectivas teóricas e deslocamentos históricos. In: Urdimento Revista de Estudos em Artes Cênicas da Universidade do Estado de Santa Catarina. v. 1, n. 10, Florianópolis, 2008.

CERTEAU, Michel de. Invenção do cotidiano-1. Artes do Fazer. Rio de Janeiro: Vozes, 2008.

DESGRANGES, Flavio. Pedagogia do espectador. São Paulo: Hucitec, 2003.

FOUCAULT, Michel. Vigiar e Punir-História da violência nas prisões. Rio de Janeiro: Vozes, 2002.

LEHMANN, Hans-Thies. Teatro pósdramático. São Paulo: Cosac Naify, 2007.

LIGIÈRO, Zeca. A performance afroamerindia. Disponível em: < http://hemi. nyu.edu/archive/text/Zeca.html>

MERLEAU-PONTY, Maurice. Fenomenologia da percepção. São Paulo: Martins Fontes, 2006.

MUNDIM, Liliane Ferreira (orientadora); BIÁ, Alessandra; MELLO, Taianã; FARES, Joaquim Vicente da Silva; IBRAIM, Juliana; VASCONCELOS, Jaqueline; NASCIMENTO, Lucas (alunospesquisadores). Diferentes olhares sobre a construção e aplicabilidade das práticas pedagógicas de ensino do teatro. Projeto de pesquisa institucional: UNIRIO 2010/2011 - CLA - Departamento de ensino de teatro RYNGAERT, Jean Pierre. Jogar, Representar. São Paulo: Cosac Naify, 2009.

SCHECHNER, Richard. Performance studies: an introduccion. $2^{\circ}$ edition. New York \& London: Routledge, 2006. 